\title{
Random Pulsewidth Matching Frequency Synthesizer With Sub-Sampling Charge Pump
}

\author{
Te-Wen Liao, Student Member, IEEE, Chia-Min Chen, Student Member, IEEE, Jun-Ren Su, and \\ Chung-Chih Hung, Senior Member, IEEE
}

\begin{abstract}
This paper presents a fast locking phase-locked loop (FLPLL) system with reference-spur reduction techniques exploiting random pulsewidth matching and a sub-sampling charge pump. Through the randomization and average of the pulsewidth and the reduction of current mismatch, the frequency synthesizer can reduce the ripples on the control voltage of the voltage-controlled oscillator in order to reduce the reference spur at the output of the phase-locked loop. A random clock generator is used to perform a random selection control. The loop bandwidth of the system can be adjusted by the control voltage so as to reduce the locking time. To demonstrate the effectiveness of the proposed spur-reduction techniques, a $2.5 \mathrm{GHz}$ to $2.7 \mathrm{GHz}$ FLPLL was designed and fabricated using a TSMC 90-nm CMOS process. The proposed circuit can achieve a phase noise of $-114 \mathrm{dBc} / \mathrm{Hz}$ at an offset frequency of $1 \mathrm{MHz}$ and reference spurs below $-74 \mathrm{dBc}$.
\end{abstract}

Index Terms-CMOS analog integrated circuits, frequency synthesizer, low spur, phase-locked loops (PLLs), sub-sampling charge pump (SSCP).

\section{INTRODUCTION}

$\mathbf{L}$ OCKING time, phase noise, and spurious-free dynamic range (SFDR) are very important perspectives in designing a frequency synthesizer. For SFDR, one of the major sources of noise is the switching noise from the charge pump at the reference frequency. The switching noise modulates the control voltage and hence the output frequency of the voltage-controlled oscillator (VCO). Two tones that reduce the system performance appears at the upper and lower sidebands around the carrier [1]. A clock with high spectral purity is required in many applications, such as in communication systems to up-convert and down-convert the wanted signals, and in analog-to-digital converts (ADCs) to accurately define the sampling moments.

Phase-locked loop (PLLs) are widely used to generate a high-accuracy clock on chip [2], [3]. For the conventional charge pump (CP), the mismatch between the $\mathrm{CP}$ up-current and down-current is the major noise source at the VCO output. The mismatch between the current sources in the CP generates the output-current ripple, which is then converted to ripple on the VCO control voltage by the low-pass filter (LPF), resulting

Manuscript received January 07, 2012; revised April 23, 2012 and May 25, 2012; accepted June 01, 2012. Date of publication August 10, 2012; date of current version November 21, 2012. This work was supported by the National Science Council. This paper was recommended by Associate Editor Jaeha Kim. The authors are with the Department of Electrical Engineering, National Chiao Tung University, Hsinchu, Taiwan (e-mail: cchung@mail.nctu.edu.tw).

Color versions of one or more of the figures in this paper are available online at http://ieeexplore.ieee.org.

Digital Object Identifier 10.1109/TCSI.2012.2206462

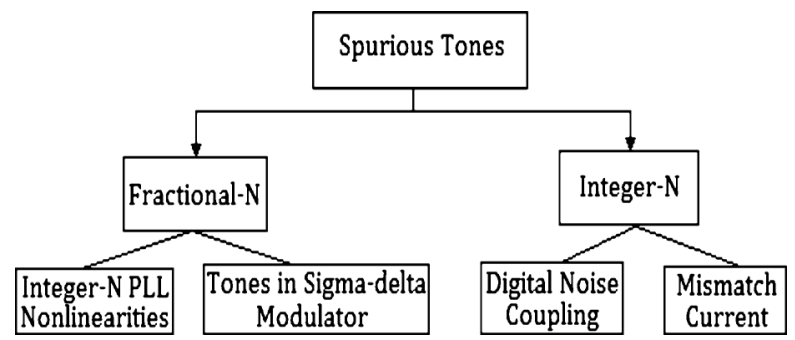

Fig. 1. Noise sources of spurious tones in PLL.

in VCO spur. A narrow loop bandwidth can be used to suppress the ripple, thereby reducing the VCO spur level. However, the PLL needs more locking time and a larger LPF area, which is difficult to implement in the SOC design. As shown in Fig. 1, the main noise sources of spurious tones of an integer-N PLL are digital noise coupling and mismatch currents. The noise sources of the fractional-N PLL are tones in the sigma-delta modulator (fractional spur) and noise from the integer-N PLL. A large bandwidth can offer a fast locking time and reduce the on-chip filter area, but it also reduces the sensitivity of the VCO output. In order to alleviate the tradeoff between low spur and large bandwidth, design techniques of random pulsewidth matching (RPWM) and sub-sampling charge pump (SSCP) have been proposed in this paper.

Several papers have been presented that focus on the CP designs to improve current source matching [4], [5] and linearization [6]. A charge-distribution mechanism on the control voltage of the voltage-controlled oscillator was used to suppress reference spur [7], and so was the technique using distributed PFDs and CPs [8]. The approach [8] involved the use of multiple small-current CPs equaling the total current value to enable the reduction of spikes on the control voltage. Pulse position modulation (PPM) was meant to select various delays in the reference and feedback clocks for distributed PFDs/CPs. However, the pulsewidth error between Up and Dn could not be resolved. Besides the use of a spur frequency-boost block [9], doubling the spur frequency and randomizing the charge redistribution time were also utilized to reduce the spurs [10]. In this paper, we propose RPWM to generate the matched CP pulsewidth, and randomize and average the ripples on the control voltage of the VCO. An SSCP is also utilized to reduce ripples on the control voltage in order to achieve a low spur level and relatively smooth spectrum. The frequency synthesizer exploits the RPWM and SSCP techniques to make the reference spur less than $-74 \mathrm{dBc}$. The frequency synthesizer has achieved a phase noise of $-114 \mathrm{dBc} / \mathrm{Hz}$ at an offset frequency of $1 \mathrm{MHz}$ and reference spurs below $-74 \mathrm{dBc}$ at $25 \mathrm{MHz}$ offset. 


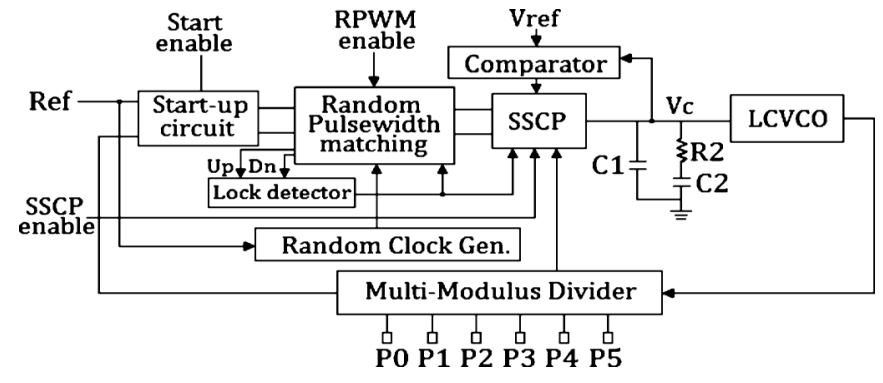

Fig. 2. Proposed fast-locking low-spur PLL.
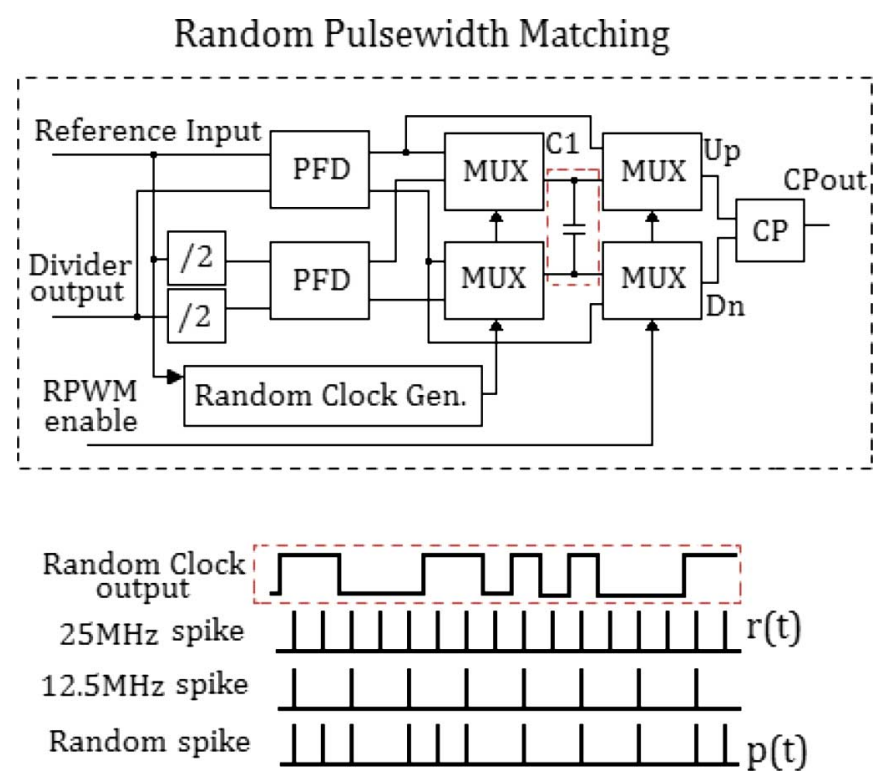

Fig. 3. Random Pulsewidth Matching (RPWM) architecture.

This paper is organized as follows. Section II discusses the RPWM and SSCP techniques. Section III describes the building blocks of the low-spur fast-locking PLL architecture. Section IV shows the experimental results and conclusions are presented in Section V.

\section{SPUR-REDUCTION ARCHITECTURES}

\section{A. Random Pulsewidth Matching (RPWM)}

The proposed fast-locking low-spur PLL is shown in Fig. 2, where RPWM and SSCP techniques are used to reduce the reference spur. A lock detector was designed into the system to indicate the locking status. The inputs of the lock detector are the two outputs (Up and Dn) of the conventional PFD, while the conventional PFD compares the phase of the feedback clock to the phase of the reference frequency. When the difference between the Up and Dn pulsewidths is less than 120 ps, the lock detector generates a "zero" signal to indicate that the PLL is locked. Fig. 3 shows the RPWM circuit, where new techniques are proposed for an integer-N frequency synthesizer. The conventional phase frequency detector (PFD) compares the phase of the divided-down VCO to the phase of the reference frequency (Ref) and generates two signals, $\mathrm{U}_{\mathrm{p}}$ and $\mathrm{D}_{\mathrm{n}}$ to control $\mathrm{CP}$. It converts the phase error into the pulsewidth difference. The net $U_{p}$ and $D_{n}$ provided by the CP phase error should be zero when the PLL is phase locked. In the conventional case, there is usually a mismatch between the pulsewidths of $\mathrm{U}_{\mathrm{p}}$ and $\mathrm{D}_{\mathrm{n}}$, which is then converted to ripple on the VCO control voltage by the LPF. When our PLL is in the locked state, the proposed RPWM will enable a 6-bit random clock generator, which can randomize $U_{p}$ and $D_{n}$ to the $C P$. As illustrated in which can randomize $U_{p}$ and $D_{n}$ to the $C P$. As illustrated in Fig. 3, in the unlocked state, we choose a conventional Ref for tracking. In the locked state, we randomly choose Ref or Ref/2 frequency in PFD for phase comparison; therefore, the spur can be randomized, smoothed, and reduced. With a reference clock period of $\mathrm{T}_{\text {ref }}$, the traditional control voltage of the $\mathrm{VCO}$, represented by $r(t)$ as shown in Fig. 3, can be simplified as [10], [11]

$$
r(t)=a_{0}+\sum_{n=1}^{\infty} a_{n} \cos \left(\frac{n \times 2 \pi}{T_{r e f}}\right) t
$$

Considering the spur at the reference frequency, the corresponding term is

$$
a_{1}=\frac{1}{T_{\text {ref }}} \int_{0}^{\text {Tref }} r(t) \cos \left(\frac{2 \pi}{T_{\text {ref }}} t\right) d t
$$

$\mathrm{p}(\mathrm{t})$ is the new control voltage of the VCO after enabling RPWM; therefore, either the reference frequency or the reference frequency divided by 2 is randomly selected in PFD for phase comparison. $\mathrm{p}(\mathrm{t})$ is the random-disturbing waveform with a period of $\mathrm{mT}_{\text {ref }}$, where $\mathrm{m}$ is determined by the random bit length s, i.e., $m=2^{\mathrm{s}}$ for an s-bits random clock generator. $p(t)$ can be expressed as

$$
p(t)=b_{0}+\sum_{k=1}^{\infty} b_{k} \cos \left(\frac{k \times 2 \pi}{m T_{\text {ref }}}\right) t
$$

Considering the random spur at the reference frequency, the corresponding term is

$$
b_{m}=\frac{1}{m T_{r e f}} \int_{0}^{m T r e f} p(t) \cos \left(\frac{2 \pi}{T_{r e f}} t\right) d t
$$

Because $p(\mathrm{t})$ can be expanded into $\mathrm{m}$ periodic pulses $S_{1}(t), S_{2}(t), \ldots, S_{m}(t)$ with mTref, each periodic pulse is the same, except for the different phase shifts. Therefore we can rewrite (4) as

$$
b_{m}=\sum_{k=1}^{m} c_{m, k}=\sum_{k=1}^{m} \frac{1}{m T_{r e f}} \int_{0}^{m T r e f} s_{k}(t) \cos \left(\frac{2 \pi}{T_{r e f}} t\right) d t
$$

According to the (5), the spur at the reference frequency is reduced by a factor of 2 to the power of the random clock bit length, that is, we can average the spur power spectrum density to accomplish a low spur level and a smooth spectrum. The magnitude of the reference spur can be approximated by the pulsewidth difference $\left(\mathrm{U}_{\mathrm{p}}-\mathrm{D}_{\mathrm{n}}=\theta_{\text {error }}\right)$ of the $\mathrm{U}_{\mathrm{p}}$ and $\mathrm{D}_{\mathrm{n}}$ signals. In our proposed RPWM circuit, as shown in Fig. 3, we add a capacitor $\mathrm{C} 1$ to average the $\mathrm{U}_{\mathrm{p}}$ and $\mathrm{D}_{\mathrm{n}}$ pulsewidths to control $\mathrm{CP}$ so as to accomplish optimal phase error to the ideal locked point. Without the RPWN circuit, we assume that the pulsewidth 

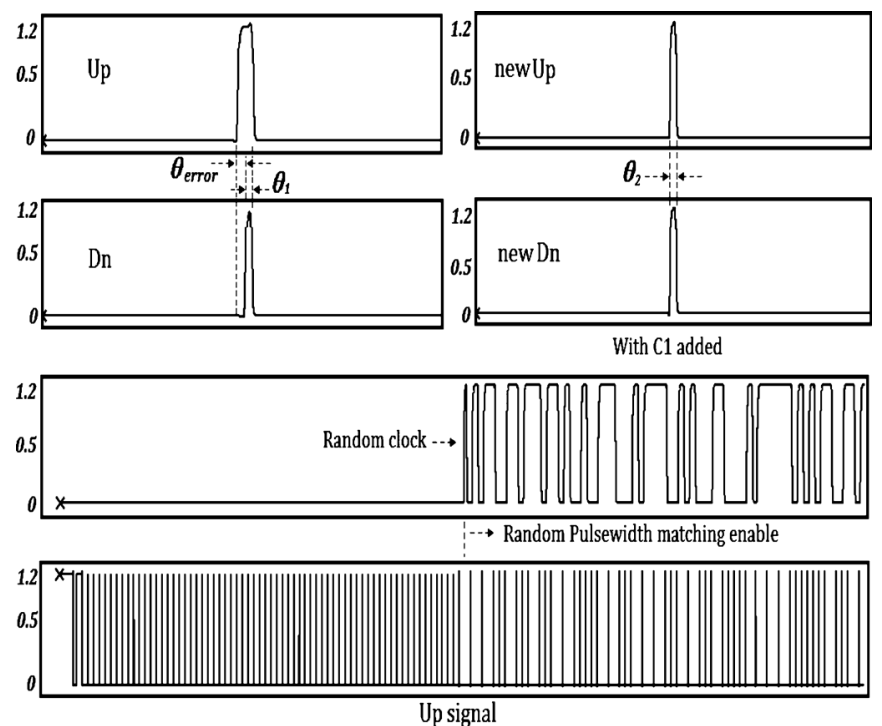

Fig. 4. RPWM timing diagram.

of $\mathrm{D}_{\mathrm{n}}$ is $\theta 1$ and that the pulsewidth of $\mathrm{U}_{\mathrm{p}}$ is $\left(\theta 1+\theta_{\text {error }}\right)$. $\mathrm{C} 1$ is designed as $2 \mathrm{pF}$; therefore, when the pulsewidth difference $\left(\theta_{\text {error }}\right)$ between $\mathrm{Up}$ and $\mathrm{Dn}$ is reduced to less than $75 \mathrm{ps}$ under all process corners, the New Up and Dn pulsewidths will be the same to reduce the reference spurs. $75 \mathrm{ps}$ was selected by setting the variation of the VCO output frequency less than $100 \mathrm{ppm}$ with a $2.5 \mathrm{GHz}$ output. A larger $\mathrm{C} 1$ enables the pulsewidths of New Up and Dn to equalize more quickly and achieve low spurs; however, this would certainly occupy more area.

When the RPWM is initially enabled, the pulsewidths of the New Up and Dn will not be equal. Capacitor C1 can average the Up and Dn pulsewidths to reduce pulsewidth error between them and the PLL loop still functions like a conventional PLL, except that capacitor $\mathrm{C} 1$ has expedited the locking process approaching the ideal locked point. With a decrease in the pulsewidth difference between Up and Dn to less than 75 ps, the New Up and Dn pulsewidths are equalized, which enables a low-spur PLL. With our proposed RPWM circuit, the pulsewidths of the new $U_{p}$ and new $D_{n}$ are the same and equal to $\theta 2=\theta 1+\left(\theta_{\text {error }} / 2\right)$, as shown in Fig. 4 . Fig. 4 shows the timing diagram of the RPWM, where the new random $U_{p}$ and $\mathrm{D}_{\mathrm{n}}$ signals are generated by a random clock and an average capacitor $\mathrm{C} 1$. The $\mathrm{V}_{\text {ripple }}$ is generated in the $\mathrm{CP}$ output of the locked PLL. The proposed RPWM can minimize the $\mathrm{V}_{\text {ripple }}$ because the pulsewidth of $U_{p}$ is equal to that of $D_{n}$; however, on the contrary, for a conventional PLL, the pulsewidth difference between $U_{p}$ and $D_{n}$ usually generates a large $V_{\text {ripple }}$ on the control voltage.

$$
\begin{aligned}
Q & =C V \Rightarrow V_{\text {ripple }}=\frac{I \cdot t}{C_{L P F}} \\
& =\frac{\left(I_{\text {pump }-U_{p}} \cdot t_{U_{p}}\right)-\left(I_{\text {pump }-D_{n}} \cdot t_{D_{n}}\right)}{C_{L P F}} \\
\frac{\left(I_{\text {pump }-U_{p}} \cdot\left(\theta_{1}+\theta_{\text {error }}\right)-I_{\text {pump }-D_{n}} \cdot \theta_{1}\right)}{C_{L P F}} & \\
> & \frac{\left(I_{\text {pump }-U_{p}}-I_{\text {pump }-D_{n}}\right) \cdot \theta_{2}}{C_{L P F}} .
\end{aligned}
$$

From (6) and (7), the ripple on the control voltage $\left(\mathrm{V}_{\text {ripple }}\right)$ is determined by the charge current of $\mathrm{CP}\left(I_{p u m p-U p}\right)$, the discharge current of CP $\left(I_{\text {pump-Dn }}\right)$, the CP charge time $\left(t_{U p}\right)$, and the CP discharge time $\left(t_{D n}\right)$. Reducing the mismatch between the charge and discharge currents $\left(I_{\text {pump-Up }}, I_{\text {pump-Dn }}\right)$ and the pulsewidth difference between the $\mathrm{U}_{\mathrm{p}}$ and $\mathrm{D}_{\mathrm{n}}$ signals $\left(t_{U p}, t_{D n}\right)$ can minimize the reference spur. However, $I_{\text {pump }}$ is restricted to the specified loop stability and the current mismatch and pulsewidth difference are difficult to prevent in a conventional integer-N PLL. Consequently, the presented RPWM randomizes the ripple to obtain a smooth spectrum, and averages the pulsewidth difference between $U_{p}$ and $D_{n}$ to reduce the ripple amplitude $\left(\mathrm{V}_{\text {ripple-conventional }}>\mathrm{V}_{\text {ripple-RPWM }}\right)$ on the voltage control line so as to reduce the reference spur in the frequency domain.

When RPWM is enabled and New Up and Dn have equalized, like all of the PLLs in a locked state, except that there is no pulsewidth error between New Up and Dn, PFD appears to lose its effectiveness, but the detection function remains in operation. Once the pulsewidth difference between Up and Dn exceeds 75 ps, the PLL loop resumes operation because there is difference between New Up and Dn, and the PLL will move towards the ideal locked point once again. Furthermore, the lock detector continues detecting the locking status. Once the PLL is unlocked, the PLL switches back to the conventional mode by disabling RPWM and resuming the locking process.

\section{B. Sub-Sampling Charge Pump (SSCP)}

As shown in Fig. 5, an SSCP was designed to reduce current mismatch $\left(\mathrm{I}_{\mathrm{Up}}, \mathrm{I}_{\mathrm{Dn}}\right)$ as well as locking time in the locked PLL. The concepts of fast locking in low-spur PLL have been discussed in the literature [12]-[14]. During the locking process of the PLL, when SSCP is not turned on, the MUX1 delivers Vbias1 to provide a tail current $\mathrm{I}_{\mathrm{B}}\left(\mathrm{Vbias} 1=\mathrm{V}_{\mathrm{DD}}\right)$. As shown in Fig. 2, the comparator will compare the control voltage of the $\mathrm{VCO}$ with a constant voltage $\mathrm{V}_{\text {ref }}$ to control the SSCP. If the Vc of the VCO is smaller than $\mathrm{V}_{\text {ref }}$, the MUX2 is enabled by the comparator output to provide an additional tail current $\mathrm{I}_{\mathrm{A}}$ to expedite the locking process and reduce the locking time. As Vc continues to increase, when Vc becomes larger than $\mathrm{V}_{\text {ref }}$, the comparator will turn off the additional tail current $\mathrm{I}_{\mathrm{A}}$, therefore reducing the tail current back to the original $\mathrm{I}_{\mathrm{B}}$. The loop bandwidth of the FLPLL system can be adjusted by the control voltage. When the control voltage is less than $V_{\text {ref }}$, a wider bandwidth can be obtained. When the control voltage becomes larger than $V_{\text {ref }}$, the loop bandwidth becomes smaller.

In PLL design, conventionally there is usually a mismatch between $\mathrm{I}_{\mathrm{Up}}$ and $\mathrm{I}_{\mathrm{Dn}}$, that is, $\mathrm{I}_{\mathrm{Up}} \neq \mathrm{I}_{\mathrm{Dn}}$, which is then converted to spikes on the $\mathrm{VCO}$ control voltage, injecting noise to the VCO and reducing the performance of the frequency synthesizer. The proposed RPWM circuit averages the $U_{p}$ and $D_{n}$ pulsewidths, which results in $t_{U_{p}}=t_{D n}$. However, in the conventional $C$, usually still exists $\mathrm{I}_{\mathrm{Up}} \neq \mathrm{I}_{\mathrm{Dn}}$. Therefore, an SSCP techniques is proposed to alleviate the mismatch between the charge current $\mathrm{I}_{\mathrm{Up}}$ and the discharge current $\mathrm{I}_{\mathrm{Dn}}$. At the locked 


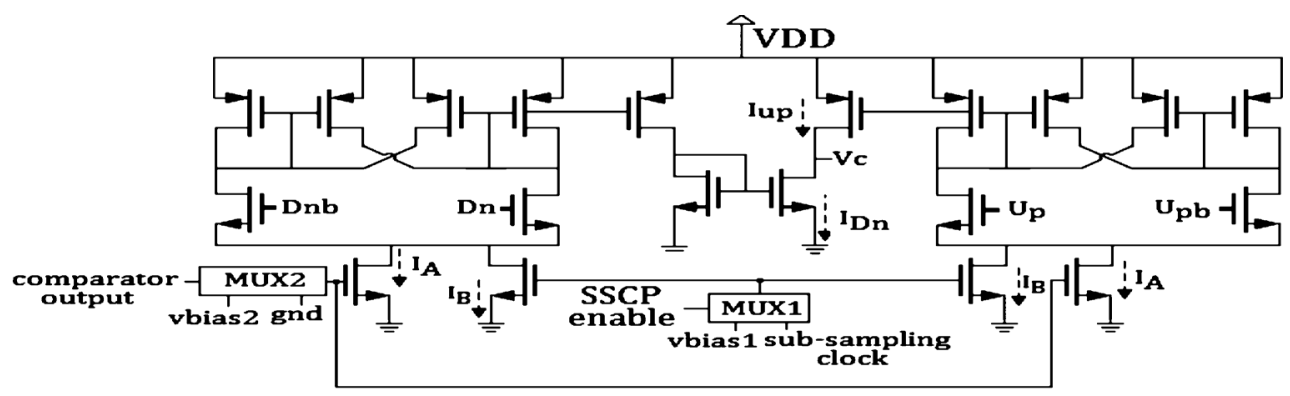

In the locked state:

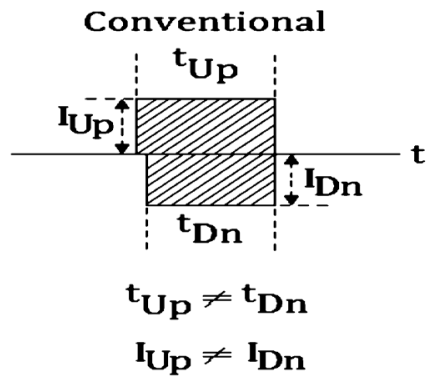

Conventional

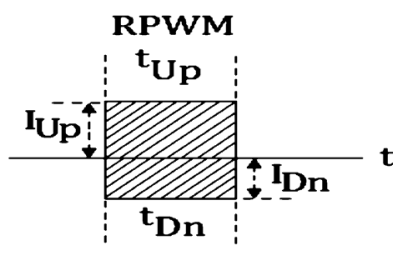

$\mathbf{t}_{\mathbf{U p}}=\mathbf{t}_{\mathbf{D n}}$

IUp $\neq \mathbf{I} \mathbf{D n}$

RPWM

$$
Q=I \cdot t=\left(t_{U p} \cdot I_{U p}\right)-\left(t_{D n} \cdot I_{D n}\right)>\left(I_{U p}-I_{D n}\right) \cdot t_{U p}>
$$

RPWM and SSCP

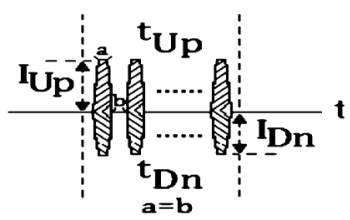

$\mathbf{t}_{\mathbf{U p}}=\mathbf{t}_{\mathbf{D n}}$

$\frac{\mathbf{I}_{\mathbf{U p}}}{2} \neq \frac{\mathbf{I}_{\mathbf{D n}}}{2}$

RPWM and SSCP

$\left(I_{U p}-I_{D n}\right) \cdot \frac{t_{U p}}{2}$

Fig. 5. Sub-sampling Charge Pump (SSCP)

state, after SSCP is enabled, the MUX1 will choose sub-sampling clock to sample the tail current $\mathrm{I}_{\mathrm{B}}$. The period of the reference clock is $40 \mathrm{~ns}$. However, the period of a sub-sampling clock is only $0.8 \mathrm{~ns}$, where the very high speed sub-sampling clock samples the tail current $\mathrm{I}_{\mathrm{B}}$ for $0.4 \mathrm{~ns}$ within each $0.8 \mathrm{~ns}$. When the tail current of the SSCP is on, the PLL operates normally with the same amount of CP current, like the conventional PLL. With such a high speed sub-sampling clock, the charge current $\mathrm{I}_{\mathrm{Up}_{\mathrm{p}}}$ and the discharge current $\mathrm{I}_{\mathrm{Dn}}$ in the time domain appear as a series of short-period trapezoidal waveforms with heights of $\mathrm{I}_{\mathrm{Up}_{\mathrm{p}}}$ and $\mathrm{I}_{\mathrm{Dn}}$, respectively, instead of one rectangular waveform, as shown in Fig. 5. If the charge current $\mathrm{I}_{\mathrm{Up}}$ and the discharge current $I_{D n}$ in the time domain were one rectangular waveform, the equivalent charge (the rectangular area) would be $\mathrm{Q}=\mathrm{I} \cdot \mathrm{t}=\left(\mathrm{I}_{\mathrm{Up}} \cdot \mathrm{t}_{\mathrm{Up}}\right) / 1$ and $\left(\mathrm{I}_{\mathrm{Dn}} \cdot \mathrm{t}_{\mathrm{Dn}}\right) / 1$. When the charge current $\mathrm{I}_{\mathrm{Up}}$ and the discharge current $\mathrm{I}_{\mathrm{Dn}}$ in the time domain is a series of trapezoidal waveforms with $\mathrm{a}=\mathrm{b}$, as shown in Fig. 5, the total area (equivalent charge) $\mathrm{Q}=\mathrm{I} \cdot \mathrm{t}=\left(\mathrm{I}_{\mathrm{Up}} \cdot \mathrm{t}_{\mathrm{Up}}\right) / 2$ and $\left(\mathrm{I}_{\mathrm{Dn}} \cdot \mathrm{t}_{\mathrm{Dn}}\right) / 2$. Thus, if there is mismatch between $\mathrm{I}_{\mathrm{Up}_{\mathrm{p}}}$ and $\mathrm{I}_{\mathrm{Dn}}$, the mismatch will be reduced to $1 / 2$ by the proposed SSCP. To sum up, for a conventional $\mathrm{CP}$ it is given as

$$
t_{U p} \neq t_{D n}, \quad \mathrm{I}_{U p} \neq \mathrm{I}_{D n}
$$

for a RPWM CP it is given as

$$
t_{U p}=t_{D n}, \quad \mathrm{I}_{U p} \neq \mathrm{I}_{D n}
$$

and for RPWM and SSCP it is given as

$$
t_{U p}=t_{D n}, \quad \frac{1}{2} \mathrm{I}_{U p} \neq \frac{1}{2} \mathrm{I}_{D n} .
$$

Therefore, the $\mathrm{V}_{\text {ripple }}$ amplitude on the control voltage can be rewritten as

$$
\begin{aligned}
V_{\text {ripple }} & =\frac{\frac{1}{2}\left(I_{\text {pump- }-U_{p}} \cdot \theta_{2}\right)-\frac{1}{2}\left(I_{\text {pump }-D_{n}} \cdot \theta_{2}\right)}{C_{L P F}} \\
& =\frac{\left(I_{U_{p}}-I_{D_{n}}\right) \cdot \theta_{2}}{2 C_{L P F}} .
\end{aligned}
$$

The SSCP technique can effectively eliminate the current ripple spike. Combining RPWM and SSCP achieves more ripple suppression $\left(\mathrm{V}_{\text {ripple-conventional }}>\mathrm{V}_{\text {ripple-RPWM }}>\right.$ $\left.\mathrm{V}_{\text {ripple-RPWM,SSCP}}\right)$. In the locked $\mathrm{VCO}$ frequency of $2.5 \mathrm{GHz}$, the frequency of $\mathrm{I}_{\mathrm{Up}}$ and $\mathrm{I}_{\mathrm{Dn}}$, the sub-sampling frequency, is $\mathrm{VCO} / 2$.

Equation (11), which we know uses the sub-sampling technique, is equivalent to increasing $\mathrm{C}_{\mathrm{LPF}}$ to get more suppression on the current spike of the locked state and obtain a smooth spectrum in the frequency domain. When RPWM is enabled, RPWM averages the pulsewidth and randomizes the $\mathrm{U}_{\mathrm{p}}$ and $\mathrm{D}_{\mathrm{n}}$ signals. The SSCP is enabled so as to accomplish a low current ripple. Another factor which also contributes to the $\mathrm{CP}$ current ripple is the charge sharing between the parasitic capacitances of the LPF, thereby using sub-sampling $\left(2 \mathrm{C}_{\mathrm{LPF}}\right)$ to minimize the parasitic charge sharing of the LPF. The proposed RPWM and SSCP can randomize, average the pulsewidth, and reduce the amplitude of the ripples on the control voltage of the VCO. The sub-sampling technique $\left(2 \mathrm{C}_{\mathrm{LPF}}\right)$ can effectively reduce the reference spur at the output of the locked PLL. 


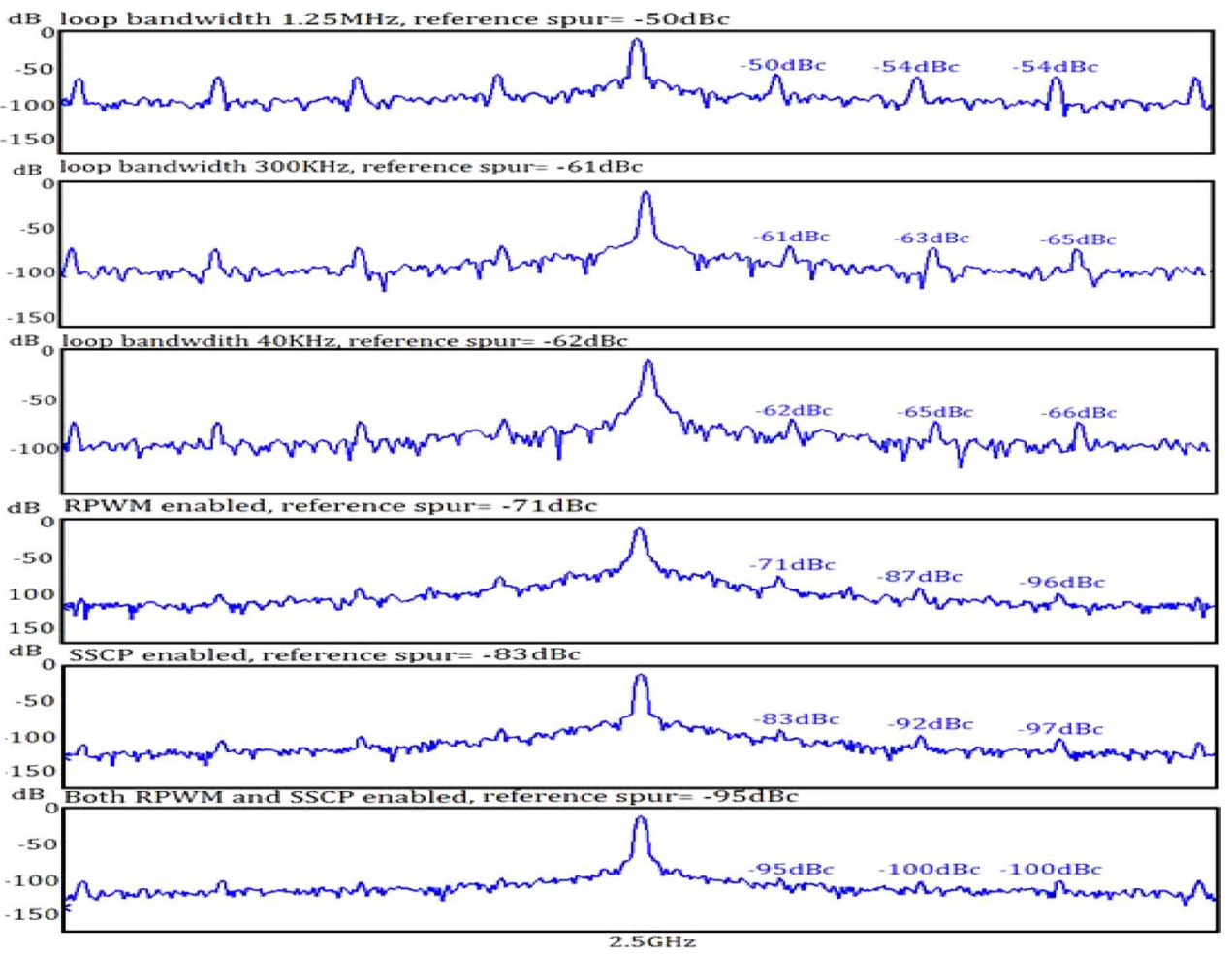

Fig. 6. Simulation of the spur reduction.

\section{SyNTHESIZER DESIGN}

\section{A. Fast-Locking Low-Spur PLL}

In this paper, as shown in Fig. 2, RPWM and SSCP are used to achieve the randomization, average, and reduction of the CP output ripple. During the operation of a conventional PLL mode, we employed a high loop-bandwidth-to-reference frequency ratio of $1 / 20$ to achieve a fast locking PLL. After the PLL is locked, RPWM and SSCP are enabled to reduce the reference spur. When the spur reduction mechanisms were enabled, the effective loop bandwidth was decreased accordingly. A reduction in loop bandwidth effectively suppressed phase noise and the reference spur. However, using the proposed RPWM and SSCP, Up and Dn are randomized and averaged, and the charge current $I_{U p}$ and the discharge current $I_{D n}$ in the time domain appear as a series of short-period trapezoidal waveforms, which reduces the reference spur even further. This can be verified by the simulation results shown in Fig. 6 . Without a spur suppression mechanism, simulation results show a reference spur of $-50 \mathrm{dBc}$. When the capacitance in the LPF is increased to reduce the loop bandwidth to $300 \mathrm{kHz}$, which is the measured loop bandwidth with only SSCP on, the reference spur becomes $-61 \mathrm{dBc}$. When the loop bandwidth was further reduced to $40 \mathrm{kHz}$, which is the measured loop bandwidth with both RPWM and SSCP on, through increased capacitance, the reference spur was $-62 \mathrm{dBc}$. However, when the spur suppression circuit for RPWM was enabled, the reference spur was $-71 \mathrm{dBc}$. When the spur suppression circuit for SSCP was enabled, the reference spur was $-83 \mathrm{dBc}$. When RPWM and SSCP were both enabled, the reference spur was $-95 \mathrm{dBc}$. These simulation results are summarized in Table I.
TABLE I

SUMmaRY OF SPUR-REDUCTION SIMULATION

\begin{tabular}{|c|c|}
\hline Loop bandwidth & Reference spur \\
\hline $\begin{array}{c}\text { Loop bandwidth } 1.25 \mathrm{MHz} \\
\text { (Original PLL without spur reduction) }\end{array}$ & $-50 \mathrm{dBc}$ \\
\hline Loop bandwidth $300 \mathrm{kHz}$ & $-61 \mathrm{dBc}$ \\
\hline Loop bandwidth $40 \mathrm{kHz}$ & $-62 \mathrm{dBc}$ \\
\hline RPWM enabled & $-71 \mathrm{dBc}$ \\
\hline SSCP enabled & $-83 \mathrm{dBc}$ \\
\hline RPWM and SSCP enabled & $-95 \mathrm{dBc}$ \\
\hline
\end{tabular}

Thus, despite a reduction in loop bandwidth, the reference spur could be effectively further reduced using the proposed techniques.

Moreover, with the proposed techniques, the loop bandwidth can been reduced without the need for a large capacitance area, providing a tremendous savings in chip area. The proposed techniques can be easily applied to other advanced processes.

\section{B. Low-Pass Filter}

The spur at the reference frequency is reduced by a factor of 2 to the power of the random clock bit length. In this proposed FLPLL, in the locked state, the frequency of the random clock is

$$
\frac{25 \mathrm{MHz}}{2^{6}-1}=396 \mathrm{KH} \text {. }
$$




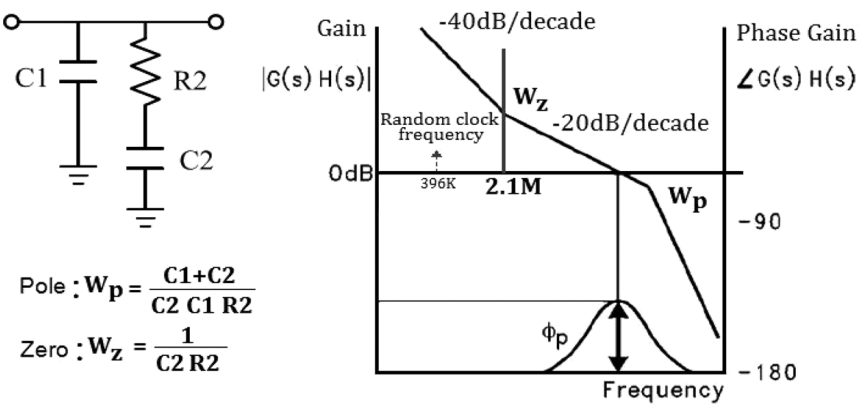

loop bandwidth=Fref/20 R2=22k, C2=21.5p C1=1.7p

Fig. 7. Design of the loop filter.

The LPF [15] was designed by using the open loop gain bandwidth and phase margin to determine the component values. As shown in Fig. 7, the phase margin will increase because of the zero and the system is stable at the unity-gain frequency. A third-order low-pass filter could be designed to attenuate the reference spur [16]; however, through the use of our proposed RPWM and SSCP techniques, the reference spur can be efficiently reduced while only a second-order LPF has been used. In other words, the proposed techniques include a second-order LPF, instead of a third-order LPF, which is adequate to provide a low-spur output clock.

\section{Multi-Modulus Divider (MMD)}

The choice of the divider architecture is essential for achieving low power dissipation and high design flexibility. One advantage of the MMD is that all the cells in the divider are identical, which can largely facilitate the layout work. The programmable divider can provide an output signal with a period of

$T_{\text {out }}=\left(2^{6}+p_{5} \cdot 2^{5}+p_{4} \cdot 2^{4}+p_{3} \cdot 2^{3}+p_{2} \cdot 2^{2}+p_{1} \cdot 2^{1}+p_{0}\right) \times T_{\text {in }}$.

Equation (14) shows that the division ratios from 64 (if all $\mathrm{CON}=0$ ) to 127 (if all $\mathrm{CON}=1$ ) are achieved [17].

\section{EXPERIMENTAL RESULTS}

The circuit was fabricated using a TSMC 90-nm 1P9M CMOS process. The fast-locking low-spur frequency synthesizer has a tunable VCO ranging from $2.3 \mathrm{GHz}$ to $2.76 \mathrm{GHz}$, and an output frequency range from $2.5 \mathrm{GHz}$ to $2.7 \mathrm{GHz}$. The reference frequency is $25 \mathrm{MHz}$. The VCO gain is $380 \mathrm{MHz} / \mathrm{V}$. Without a spur suppression mechanism, experimental results show measured reference spurs of $-39 \mathrm{dBc}$ and $-36 \mathrm{dBc}$ at $2.5 \mathrm{GHz}$ and $2.6 \mathrm{GHz}$ of the locked frequency by a $25 \mathrm{MHz}$ frequency offset, respectively, as shown in Figs. 8 and 12. When the spur suppression circuit for RPWM is enabled, the measured reference spurs are $-49 \mathrm{dBc}$ and $-43 \mathrm{dBc}$ at $2.5 \mathrm{GHz}$ and $2.6 \mathrm{GHz}$, respectively, as shown in Figs. 9 and 13. When the spur suppression circuit for SSCP is enabled, the measured reference spurs are $-65 \mathrm{dBc}$ and $-64 \mathrm{dBc}$ at $2.5 \mathrm{GHz}$ and 2.6 GHz, respectively, as shown in Figs. 10 and 14. When RPWM and SSCP are both enabled, the measured reference spurs are $-74 \mathrm{dBc}$ and $-70 \mathrm{dBc}$ at $2.5 \mathrm{GHz}$ and $2.6 \mathrm{GHz}$,

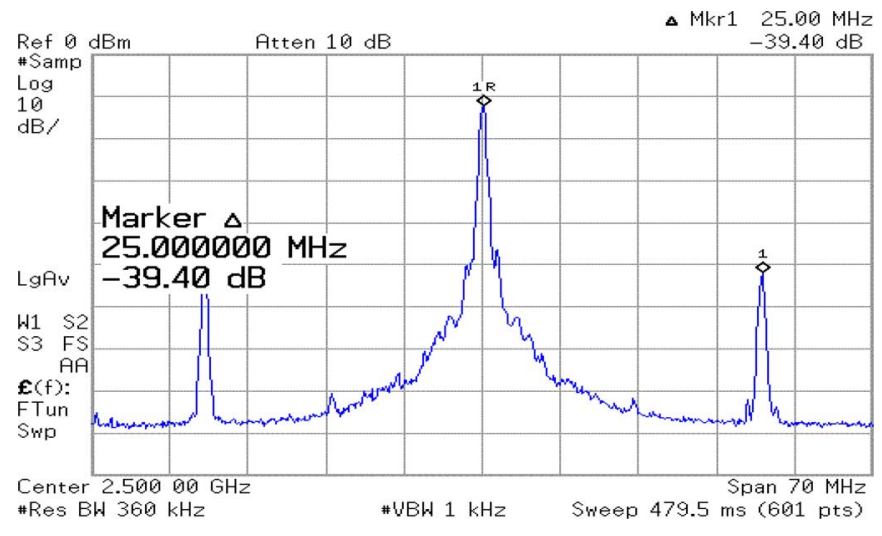

Fig. 8. Measured reference spurs at $2.5 \mathrm{GHz}$ locked frequency.

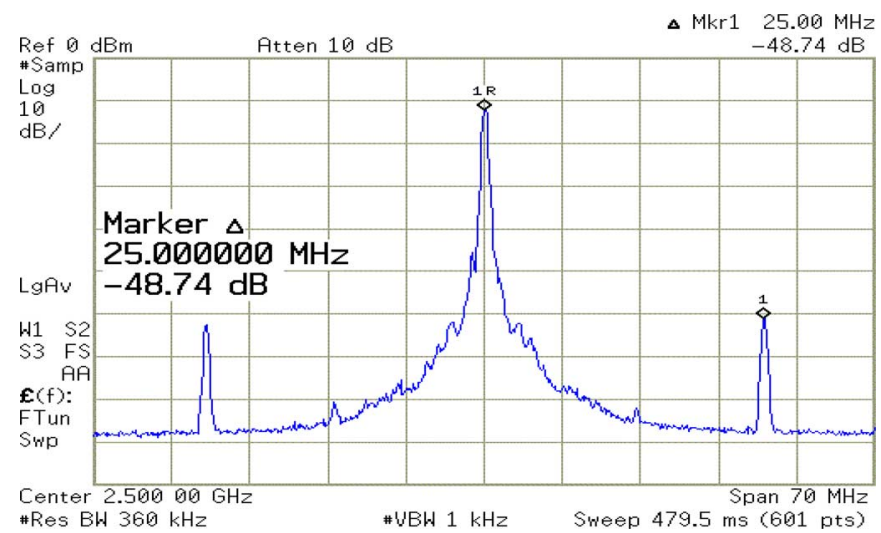

Fig. 9. Measured reference spurs at $2.5 \mathrm{GHz}$ with RPWM on.

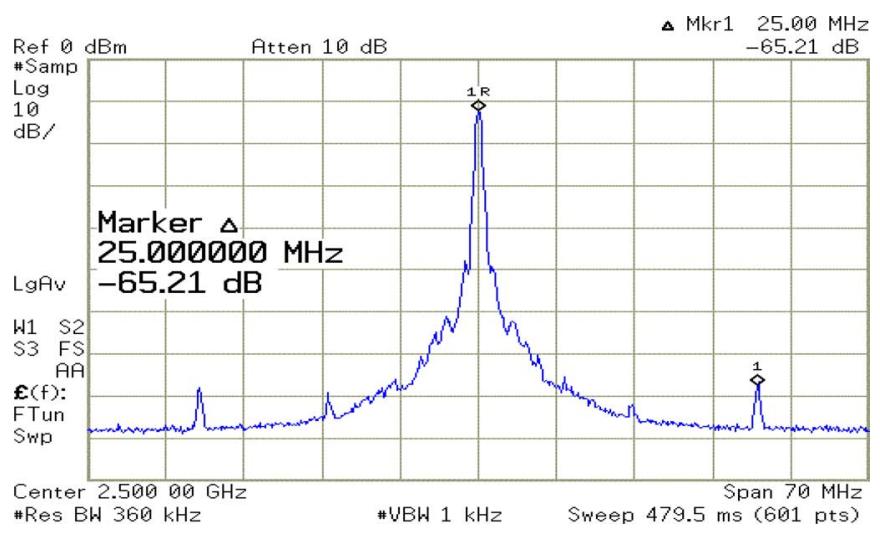

Fig. 10. Measured reference spurs at $2.5 \mathrm{GHz}$ with SSCP on.

respectively, as shown in Figs. 11 and 15. The phase noise was $-107 \mathrm{dBc} / \mathrm{Hz}$ with a $40 \mathrm{kHz}$ offset; with only RPWM on, the phase noise was $-104 \mathrm{dBc} / \mathrm{Hz}$ with a $40 \mathrm{kHz}$ offset; with only SSCP on, the phase noise was $-102 \mathrm{dBc} / \mathrm{Hz}$ with a $40 \mathrm{kHz}$ offset; with both RPWM and SSCP on, the phase noise was $-102 \mathrm{dBc} / \mathrm{Hz}$ with a $40 \mathrm{kHz}$ offset. These results are illustrated in Figs. 16, 17, 18 and 19, respectively. The proposed techniques increase phase noise slightly. Enabling the spur reduction mechanisms decreased the effective loop bandwidth. With the spur-reduction functions off, the measured loop bandwidth was $860 \mathrm{KHz}$. With RPWM on, the measured loop bandwidth was $600 \mathrm{KHz}$; with SSCP on, the measured loop bandwidth was $300 \mathrm{KHz}$; when both RPWM and SSCP were turned on, the measured loop bandwidth was $40 \mathrm{KHz}$. 


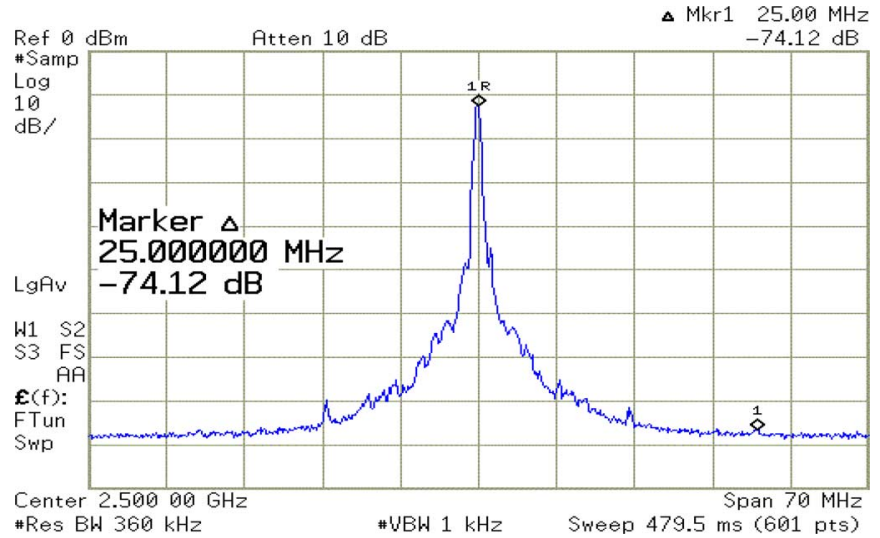

Fig. 11. Measured reference spurs at $2.5 \mathrm{GHz}$ with both RPWM and SSCP on.

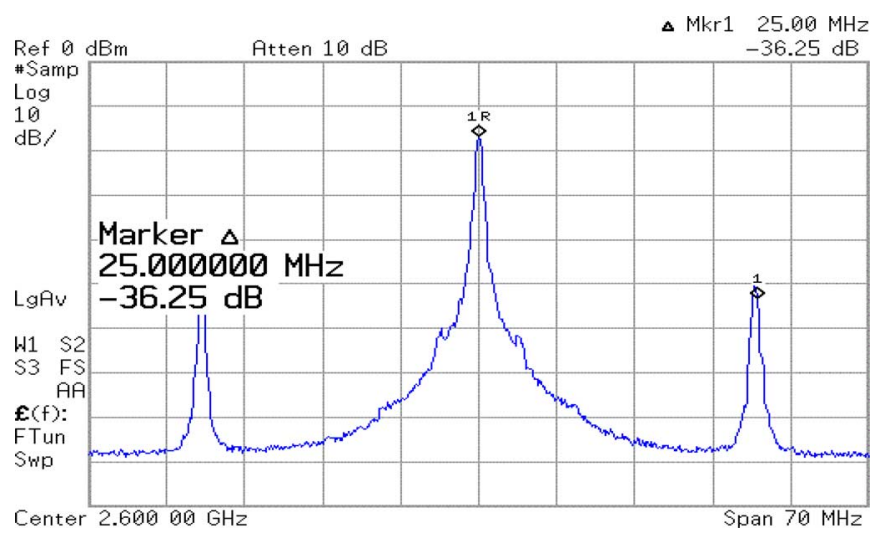

Fig. 12. Measured reference spurs at $2.6 \mathrm{GHz}$ locked frequency.

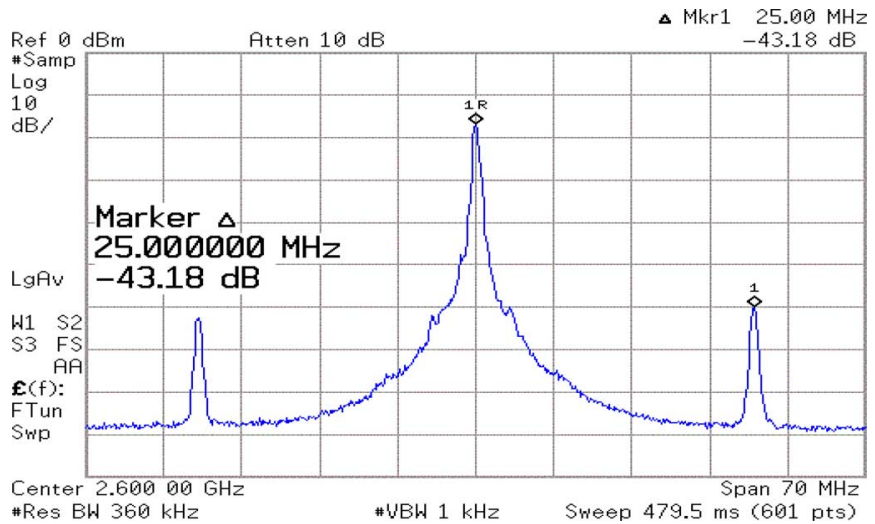

Fig. 13. Measured reference spurs at $2.6 \mathrm{GHz}$ with RPWM on.

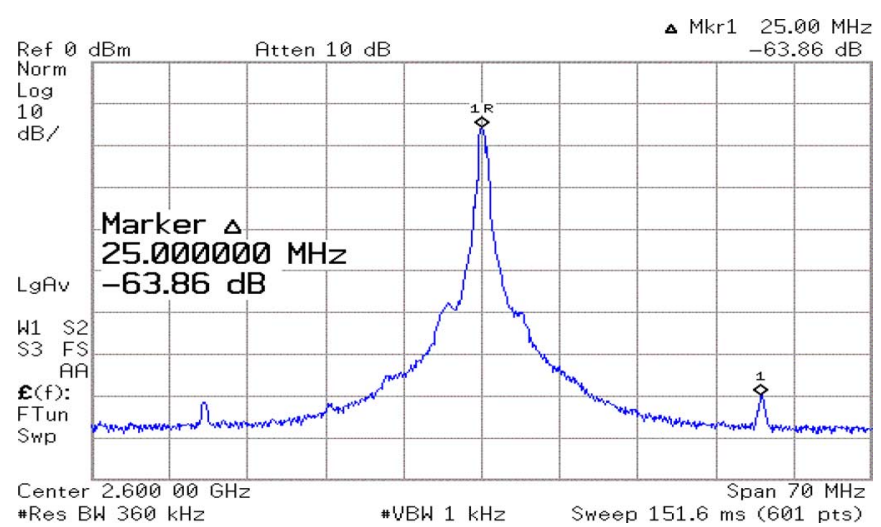

Fig. 14. Measured reference spurs at $2.6 \mathrm{GHz}$ with SSCP on.

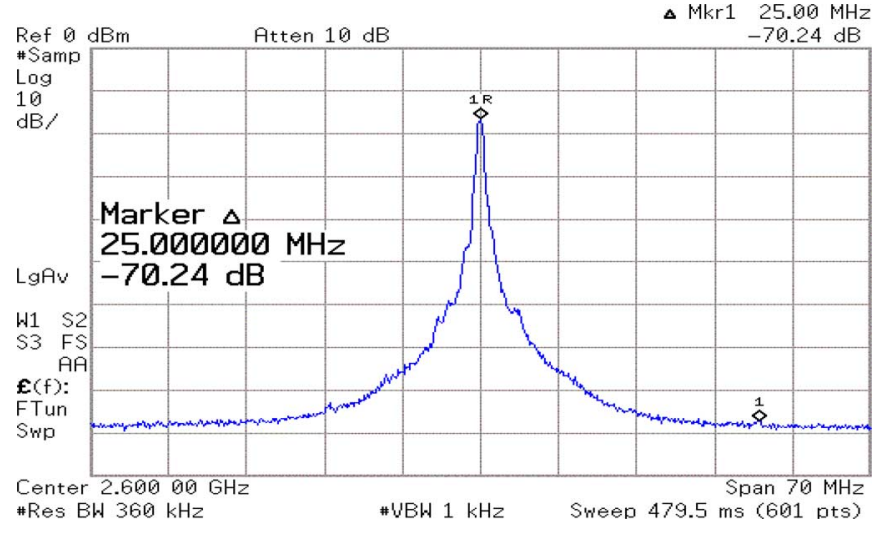

Fig. 15. Measured reference spurs at $2.6 \mathrm{GHz}$ with both RPWM and SSCP on.

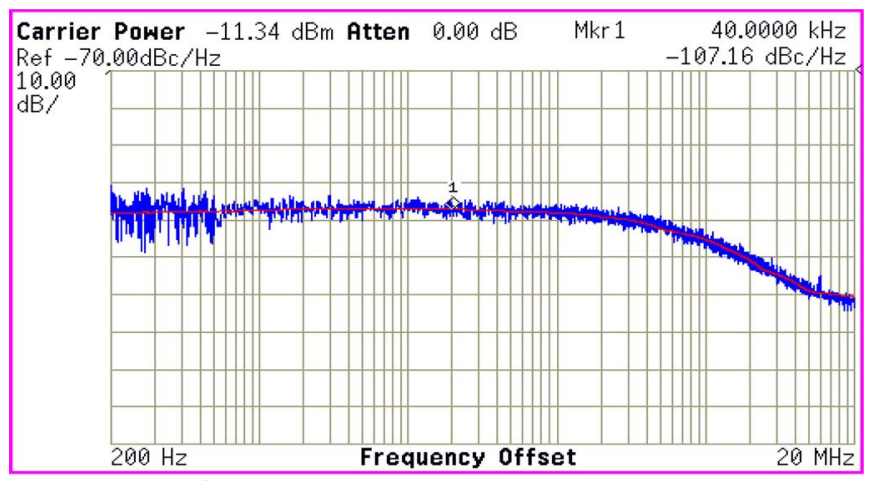

Conventional PLL

Fig. 16. Measured phase noise with $40 \mathrm{kHz}$ offset at $2.5 \mathrm{GHz}$.

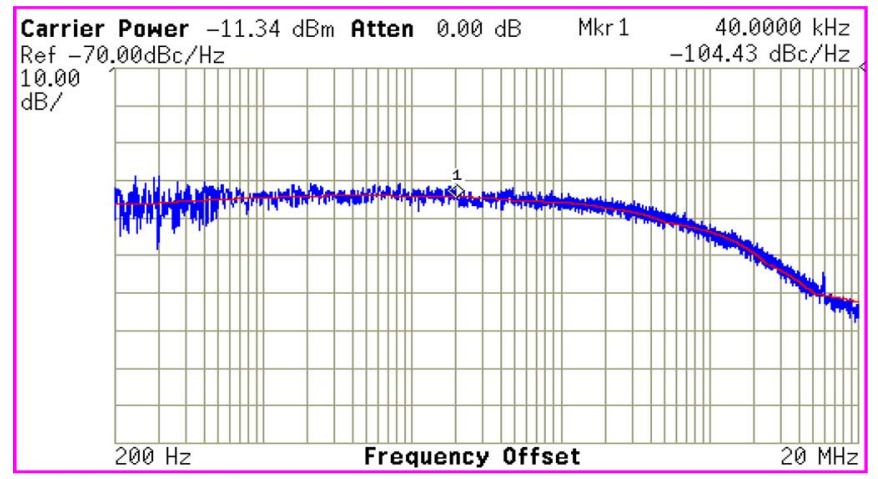

RPWM enabled

Fig. 17. Measured phase noise with $40 \mathrm{kHz}$ offset at $2.5 \mathrm{GHz}$ with RPWM on.

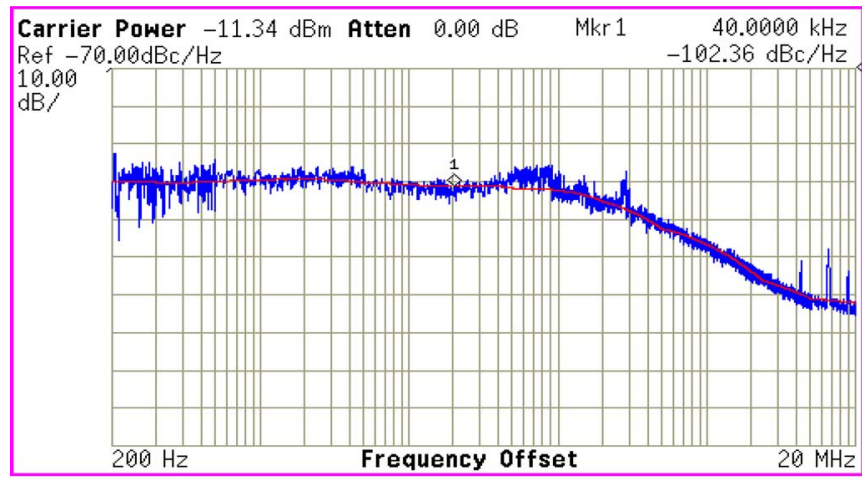

\section{SSCP enabled}

Fig. 18. Measured phase noise with $40 \mathrm{kHz}$ offset at $2.5 \mathrm{GHz}$ with SSCP on. 


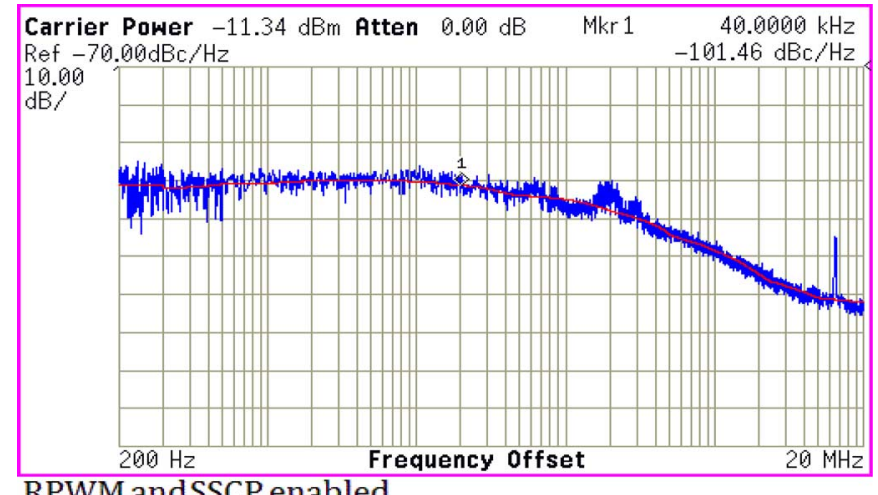

\section{RPWM andSSCP enabled}

Fig. 19. Measured phase noise with $40 \mathrm{kHz}$ offset at $2.5 \mathrm{GHz}$ with both RPWM and SSCP on.

TABLE II

Phase NoISE PERformance

\begin{tabular}{|c|c|c|c|c|}
\hline $\begin{array}{c}\text { Phase } \\
\text { noise }\end{array}$ & $\begin{array}{c}\text { Conventional } \\
\text { PLL }\end{array}$ & $\begin{array}{c}\text { RPWN } \\
\text { enabled }\end{array}$ & $\begin{array}{c}\text { SSCP } \\
\text { enabled }\end{array}$ & $\begin{array}{c}\text { RPWN and } \\
\text { SSCP enabled }\end{array}$ \\
\hline$@ 40 \mathrm{kHz}$ & $\begin{array}{c}-107 \\
\mathrm{dBc} / \mathrm{Hz}\end{array}$ & $\begin{array}{c}-104 \\
\mathrm{dBc} / \mathrm{Hz}\end{array}$ & $\begin{array}{c}-102 \\
\mathrm{dBc} / \mathrm{Hz}\end{array}$ & $\begin{array}{c}-102 \\
\mathrm{dBc} / \mathrm{Hz}\end{array}$ \\
\hline$@ 600 \mathrm{kHz}$ & $\begin{array}{c}-110 \\
\mathrm{dBc} / \mathrm{Hz}\end{array}$ & $\begin{array}{c}-109 \\
\mathrm{dBc} / \mathrm{Hz}\end{array}$ & $\begin{array}{c}-108 \\
\mathrm{dBc} / \mathrm{Hz}\end{array}$ & $\begin{array}{c}-110 \\
\mathrm{dBc} / \mathrm{Hz}\end{array}$ \\
\hline$@ 1 \mathrm{MHz}$ & -113 & -111 & -113 & -114 \\
$\mathrm{dBc} / \mathrm{Hz}$ & $\mathrm{dBc} / \mathrm{Hz}$ & $\mathrm{dBc} / \mathrm{Hz}$ & $\mathrm{dBc} / \mathrm{Hz}$ \\
\hline $\begin{array}{l}\text { Measured } \\
\text { bandwidth }\end{array}$ & $860 \mathrm{kHz}$ & $600 \mathrm{kHz}$ & $300 \mathrm{kHz}$ & $40 \mathrm{kHz}$ \\
\hline
\end{tabular}

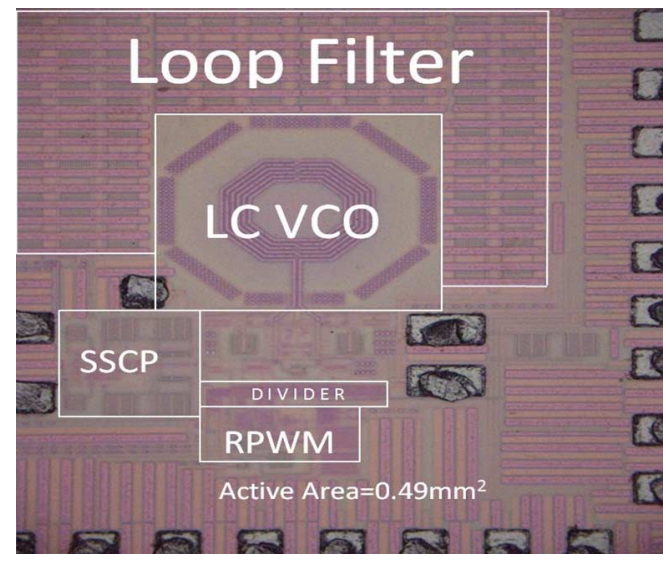

Fig. 20. Die micrograph.

With a reduction in the loop bandwidth, the phase noise can still be well suppressed. The phase noise performance under different conditions is summarized in Table II. The die micrograph is shown in Fig. 20. The area of the synthesizer is $0.49 \mathrm{~mm}^{2}$, including the LPF.

The performance summary and comparisons are provided in Table III and Table IV, respectively. This work has lower reference spur levels by exploiting the RPWM and SSCP techniques
TABLE III

Performance Summary

\begin{tabular}{|c|c|}
\hline Items & Performance \\
\hline Technology & TSMC 90-nm 1P9M CMOS \\
\hline Power Supply & $1.2 \mathrm{~V}$ \\
\hline Reference Fre. & $25 \mathrm{MHz}$ \\
\hline LC VCO & $2.3 \mathrm{GHz}-2.76 \mathrm{GHz}$ \\
\hline Divider ratio & 100 \\
\hline $\mathrm{K}_{\mathrm{vco}}$ & $380 \mathrm{MHz} / \mathrm{V}$ \\
\hline Spur level & $-39 \mathrm{dBc}$ \\
\hline Spur level ( RPWM on) & $-49 \mathrm{dBc}$ \\
\hline Spur level (SSCP on) & $-65 \mathrm{dBc}$ \\
\hline Spur level (RPWM and SSCP on) & $-74 \mathrm{dBc}$ \\
\hline Spur reduction & $35 \mathrm{~dB}$ \\
\hline Phase noise@ $40 \mathrm{kHz}$ (conventional) & $-107 \mathrm{dBc} / \mathrm{Hz}$ \\
\hline $\begin{array}{c}\text { Phase noise @ } 40 \mathrm{kHz} \\
\text { (RPWM enabled) }\end{array}$ & $-104 \mathrm{dBc} / \mathrm{Hz}$ \\
\hline $\begin{array}{c}\text { Phase noise@ } 40 \mathrm{kHz} \\
\text { (SSCP enabled) }\end{array}$ & $-102 \mathrm{dBc} / \mathrm{Hz}$ \\
\hline $\begin{array}{c}\text { Phase noise @ } 40 \mathrm{kHz} \\
\text { (Both RPWM and SSCP enabled) }\end{array}$ & $-102 \mathrm{dBc} / \mathrm{Hz}$ \\
\hline Power consumption & $12 \mathrm{~mW}$ \\
\hline
\end{tabular}

with the 2nd-order LPF frequency synthesizer. The reference spurs are lowered by about $35 \mathrm{~dB}$ (from -39 to $-49 \mathrm{dBc}$ for RPWM enabled, and from -49 to $-74 \mathrm{dBc}$ with both RPWM and SSCP on), which is still far below the simulated reduction of $45 \mathrm{~dB}$ (from -50 to $-95 \mathrm{dBc}$ with both RPWM and SSCP on). The noise floor increases by PCB coupling noise and power supply injection noise. As compared with other works, this work gets more suppression of reference spurs while the phase noise still maintains at a low level. The total power consumption of the proposed synthesizer is $12 \mathrm{~mW}$.

\section{CONCLUSIONS}

The conventional charge pump-based high performance PLL has been facing increasing challenges imposed to scale with sub-micron VLSI technologies. The design tradeoffs among the PLL loop bandwidth, reference noise, VCO noise, and divider noise limit the usefulness of the integer-N PLL. In this paper, design techniques to reduce the PLL reference spurs and to achieve fast locking have been proposed. The low spur frequency synthesizer, which can randomize, average the pulsewidth, and reduce the amplitude of the ripples on the VCO control voltage in order to reduce the proposed. To demonstrate the effectiveness of the proposed reference spur at the output of the locked PLL, has been spur-reduction techniques, a $2.5 \mathrm{GHz}-2.7 \mathrm{GHz}$ 
TABLE IV

PERFormance COMPARISON With OTHER WORKS

\begin{tabular}{|c|c|c|c|c|c|c|}
\hline & {$[1]$} & [9] & {$[14]$} & [18] & [19] & This work \\
\hline \multirow{2}{*}{ Process } & $0.18 \mathrm{um}$ & $0.18 \mathrm{um}$ & $0.18 \mathrm{um}$ & $0.18 \mathrm{um}$ & $0.18 \mathrm{um}$ & $90 \mathrm{~nm}$ \\
\hline & CMOS & CMOS & CMOS & CMOS & CMOS & CMOS \\
\hline Supply & 1.8 & 1.8 & 1.8 & 1.8 & 1.8 & 1.2 \\
\hline Ref. freq. & $12 \mathrm{MHz}$ & $1 \mathrm{MHz}$ & $20 \mathrm{MHz}$ & $55.25 \mathrm{MHz}$ & $50 \mathrm{MHz}$ & $25 \mathrm{MHz}$ \\
\hline Freq. $(\mathrm{GHz})$ & 2.4 & $4.8 / 2.4$ & $2.2-2.6$ & 2.21 & 3.6 & $2.5-2.7$ \\
\hline $\mathrm{F}_{\mathrm{BW}} / \mathrm{F}_{\mathrm{ref}}$ & $1 / 12$ & N/A & $1 / 74$ & N/A & $1 / 50$ & $1 / 20$ \\
\hline Loop filter & N/A & 2nd & $\mathrm{N} / \mathrm{A}$ & N/A & N/A & 2nd \\
\hline $\begin{array}{c}\text { Phase } \\
\text { noise@ }(\mathrm{dBc} / \mathrm{Hz})\end{array}$ & -108@100kHz & $\begin{array}{r}-104 /-110 \\
\text { @ } 1 \mathrm{MHz}\end{array}$ & -105.5@1MHz & -126@200kHz & -93@100kHz & -102@40kHz \\
\hline Ref. spur $(\mathrm{dBc})$ & -70 & -55 & -52 & -46 & -74 & -74 \\
\hline Power(mW) & 39 & 18 & 22 & 7.6 & 110 & 12 \\
\hline
\end{tabular}

FLPLL is designed and fabricated using a TSMC 90-nm CMOS process and has achieved a phase noise of $-114 \mathrm{dBc} / \mathrm{Hz}$ at a $1 \mathrm{MHz}$ offset frequency and reference spurs below $-74 \mathrm{dBc}$. The proposed techniques can be easily applied to other advanced processes.

\section{ACKNOWLEDGMENT}

The authors would like to thank the National Chip Implementation Center for supporting the chip fabrication.

\section{REFERENCES}

[1] K. J. Wang, A. Swaminathan, and I. Galton, "Spurious-tone suppression techniques applied to wide-bandwidth $2.4 \mathrm{GHz}$ fractional-N PLL," in IEEE ISSCC Dig. Tech. Papers, 2008, pp. 342-343.

[2] L. Lu, Z. Gong, Y. Liao, H. Min, and Z. Tang, "A 975-to-1960 MHz fast-locking fractional-N synthesizer with adaptive bandwidth control and $4 / 4.5$ prescaler for digital TV tuners," in ISSCC Dig. Tech. Papers, Feb. 2009, pp. 396-397.

[3] X. Kung and N. Wu, "A fast-setting monolithic PLL frequency synthesizer with direct frequency presetting," in ISSCC Dig. Tech. Papers, Feb. 2006, pp. 204-205.

[4] C. M. Hung and K. K. O. , "A full integrated 1.5-V 5.5-GHz CMOS phase-locked loop," IEEE J. Solid-State Circuits, vol. 37, no. 4, pp. 521-525, Apr. 2002.

[5] C.-L. Ti, Y.-H. Liu, and T.-H. Lin, "A 2.4-GHz fractional-N PLL with a PFD/CP linearization and an improved CP circuit," in IEEE ISCAS, May 2008, pp. 1728-1731.

[6] S. Pamarti, L. Jansson, and I. Galton, "A wideband 2.4-GHz deltasigma fractional-N PLL with $1-\mathrm{Mb} / \mathrm{s}$ in-loop modulation," IEEE $J$. Solid-State Circuits, vol. 39, no. 1, pp. 49-62, Jan. 2004.

[7] J. Choi, W. Kim, and K. Lim, "A spur suppression technique using an edge-interpolator for a charge pump PLL," IEEE Trans. Very Large Scale Integration systems, vol. 20, no. 5, pp. 969-973, May 2012.

[8] T.-C. Lee and W.-L. Lee, "A spur suppression technique for phase-locked frequency synthesizers," in ISSCC Dig. Tech. Papers, Feb. 2006, pp. 2432-2433.
[9] M. Elsayed, M. Abdul-Latif, and E. Sánchez-Sinencio, "A spur-frequency boosting PLL with $-74 \mathrm{dBc}$ reference-spur rejection in $90 \mathrm{~nm}$ digital CMOS," in IEEE RFIC Symposium, June 2011, pp. 521-524.

[10] C.-F. Liang, H.-H. Chen, and S.-I. Liu, "Spur-suppression techniques for frequency synthesizers," IEEE Trans. Circuits and Systems II, vol. 54, no. 8, pp. 653-657, Aug. 2007.

[11] E. Juárez-Hernández and A. Díaz-Sánchez, "A novel CMOS charge pump with positive feedback for PLL applications," in IEEE International Conference on Electronics, Circuit and Systems, Malta, Sep. 2001, vol. 1, pp. 349-352.

[12] X. Gao, E. A. M. Klumperink, M. Bohsali, and B. Nauta, "Spur reduction techniques for phase-locked loops exploiting a sub-sampling phase detector," IEEE J. Solid-State Circuits, vol. 45, no. 9, pp. 1809-1821, Sep. 2010

[13] T.-H. Lin, C.-L. Ti, and Y.-H. Liu, "Dynamic current-matching charge pump and gated-offset linearization technique for delta-sigma fractional- $N$ PLLs," IEEE Trans. Circuits Syst.-I, vol. 56, no. 5, pp. 877-885, May 2009.

[14] X. Gao, E. A. M. Klumperink, M. Bohsali, and B. Nauta, "A low-noise sub-sampling PLL in which divider noise is eliminated and $\mathrm{PD} / \mathrm{CP}$ noise is not multiplied by $N^{2}$," IEEE J. Solid-State Circuits, vol. 44, no. 12, pp. 3253-3263, Dec. 2009.

[15] U. L. Rohde, Digital PLL Frequency Synthesizers Theory and Design. : Prentice-Hall, 1983.

[16] "An analysis and performance evaluation of a passive filter design technique for charge pump phase-locked loops," National Semiconductor Application Note 1001 National Semiconductor Corporation. Santa Clara, CA, May 1996.

[17] C. S. Vaucher, I. Ferencic, M. Locher, S. Sedvallson, U. Voegeli, and Z. Wang, "A family of low-power truly modular programmable dividers in standard 0.35- $\mu \mathrm{m}$ CMOS technology," IEEE J. Solid-State Circuits, vol. 35 , no. 7 , pp. $1039-1045$, July 2000 .

[18] X. Gao, E. A. M. Klumperink, M. Bohsali, and B. Nauta, "A $2.2 \mathrm{GHz}$ $7.6 \mathrm{~mW}$ sub-sampling PLL with $-126 \mathrm{dBc} / \mathrm{Hz}$ in-band phase noise and 0.15 psrms jitter in $0.18 \mu \mathrm{m}$ CMOS," presented at the ISSCC Dig. Tech. Papers, Feb. 2009, pp. 392-393.

[19] S. E. Meninger and M. H. Perrott, "A 1 MHz bandwidth $3.6 \mathrm{GHz} 0.18$ $\mu \mathrm{m}$ CMOS fractional-N synthesizer utilizing a hybrid PFD/DAC structure for reduced broadband phase noise," IEEE J. Solid-State Circuits, vol. 41, no. 4, pp. 966-980, Apr. 2006. 


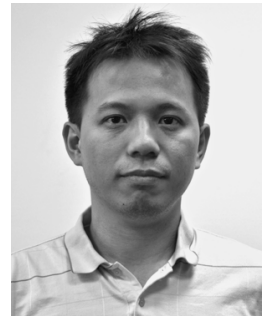

Te-Wen Liao (S'08) was born in Chung-Li, Taiwan, in 1981. He received the M.S. degree in electrical engineering from National Chiao Tung University, Hsinchu, Taiwan, in 2008. He is currently working toward the Ph.D. degree in the Department of Electrical Engineering, National Chiao Tung University, Hsinchu, Taiwan.

His research interests include high-speed CMOS circuit design such as phase-locked loops, all-digital pulsewidth-control circuits, and delay-locked loops.

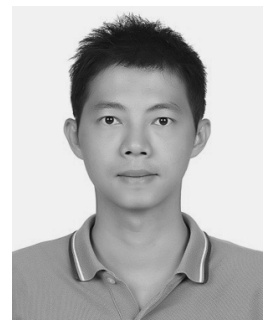

Chia-Min Chen received the M.S. degree in electrical engineering from National Chiao Tung University, Hsinchu, Taiwan, in 2006 . He is currently working toward the Ph.D. degree in the Department of Electrical Engineering, National Chiao Tung University, Hsinchu, Taiwan.

His research interests include mixed-signal integrated circuit design, power management integrated circuits, and energy-efficient integrated circuits and systems.

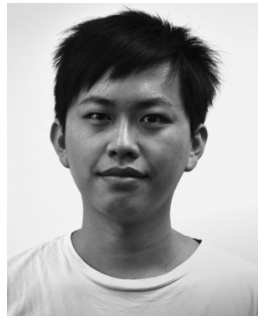

Jun-Ren Su was born in Tao-Yuan, Taiwan, in 1985. $\mathrm{He}$ received the B.S. degree in electrical engineering from National Chiao Tung University, Hsinchu, Taiwan, in 2008. He is currently working toward the $\mathrm{Ph} . \mathrm{D}$. degree in the Department of Electrical Engineering, National Chiao Tung University, Hsinchu, Taiwan.

His research interests include high-speed CMOS circuit design such as PWCL and ADPLL.

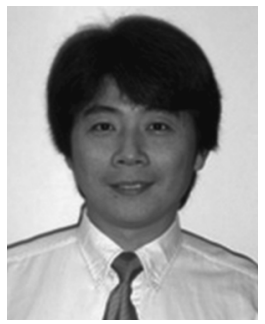

Chung-Chih Hung (M'98-SM'07) received the B.S. degree in electrical engineering from National Taiwan University, Taipei, Taiwan, in 1989, and the M.S. and Ph.D. degrees in electrical engineering from The Ohio State University, Columbus, $\mathrm{OH}$, in 1993 and 1997, respectively.

From 1989 to 1991, he served in the Taiwan Marine Corps as a Communication officer. From 1997 to 2003, he worked for several IC design companies in San Jose, CA and San Diego, CA, where he held analog circuit design manager and director positions. Since 2003, he has been with National Chiao Tung University, Hsinchu, Taiwan, where he is currently an Associate Professor in the Department of Electrical Engineering. His research interests include the design of analog and mixed-signal integrated circuits for communication and high-speed applications. 